\title{
A Method of Air Targets Complex Recognition in Air-Based Pulse-Doppler Radar at the Stage of Primary Signals Processing
}

\author{
Alexander V. Bogdanov, Alexander A. Lobanov*, \\ Alexander A. Kuchin and Valentin A. Golubenko \\ Military Academy of Aero-Space Defence \\ named after the Marshal of Soviet Union G.K. Zhukov \\ Tver, Russian Federation
}

Received 20.08.2019, received in revised form 05.11.2019, accepted 21.01.2020

Abstract. This paper deals with developed procedures of recognition air targets state based on "single target, with their number - group targets with number of group targets and targets in each group", the class of single target based on "turbojet aircraft - turboprop aircraft - helicopter missile" the type of single target based on "turbojet aircraft", separated air target and types of group air target among turbojet aircraft class due to flight-experimental research of the information properties radar signals, echoed from different classes and types of air targets. In addition, the authors developed the method of air targets complex recognition in air-based pulse-Doppler radar at the stage of primary signals processing that combined this recognition procedures.

Keywords: pulse-Doppler radar, recognition of air targets, spectral Doppler portrait, target type, flight experiment, air-frame, early stages of low pressure compressor, radar echo.

Citation: Bogdanov A.V., Lobanov A.A., Kuchin A.A., Golubenko V.A. A method of air targets complex recognition in airbased pulse-doppler radar at the stage of primary signals processing, J. Sib. Fed. Univ. Eng. \& Technol., 2020, 13(3), 311-327. DOI: $10.17516 / 1999-494 X-0223$

(C) Siberian Federal University. All rights reserved

This work is licensed under a Creative Commons Attribution-Non Commercial 4.0 International License (CC BY-NC 4.0).

* Corresponding author E-mail address: Xantrax1956@mail.ru 


\title{
Метод комплексного распознавания воздушных целей в импульсно-доплеровских РЛС воздушного базирования на этапе первичной обработки сигналов
}

\author{
А.В. Богданов, А.А. Лобанов, \\ А.А. Кучин, В.А. Голубенко \\ Военная академия воздушно-космической обороны \\ им. Маршала Советского Союза Г. К. Жукова \\ Российская Федерация, Тверь
}

Аннотация. В статье на основе результатов летно-экспериментальных исследований информационных свойств радиолокационных сигналов, отраженных от различных классов и типов воздушных целей, разработаны процедуры распознавания воздушных целей по принципу «одиночная цель, с их количеством - групповая цель с количеством групп целей и целей в каждой группе», класса одиночной воздушной цели по принципу «самолет с турбореактивным двигателем - самолет с турбовинтовым двигателем - вертолет - ракета», типа одиночной цели из класса «самолет с турбореактивным двигателем», разделяющейся цели и типового состава групповой воздушной цели из класса «самолеты с турбореактивными двигателями», a также разработан метод комплексного распознавания воздушных целей в бортовой радиолокационной станции истребителя на этапе первичной обработки радиолокационных сигналов, объединяющий данные процедуры распознавания.

Ключевые слова: импульсно-доплеровская бортовая радиолокационная станция, распознавание воздушных целей, спектральный доплеровский портрет, тип цели, летно-экспериментальные исследования, фюзеляж, первая ступень компрессора низкого давления, отраженный радиолокационный сигнал.

Цитирование: Богданов, А.В. Метод комплексного распознавания воздушных целей в импульсно-доплеровских РЛС воздушного базирования на этапе первичной обработки сигналов / А.В. Богданов, А.А. Лобанов, А.А. Кучин, В.А. Голубенко // Журн. Сиб. федер. ун-та. Техника и технологии, 2020. 13(3). С. 311-327. DOI: 10.17516/1999-494X-0223

В [1] предложен вариант концепции радиолокационного (РЛ) распознавания воздушных целей (ВЦ) в бортовой радиолокационной станции (БРЛС) перспективного истребителя, построенной по импульсно-доплеровскому принципу обработки РЛ-сигналов в сантиметровом диапазоне волн при ее работе в режиме высокой частоты повторения зондирующих немодулированных импульсов. В основу разработки данного варианта концепции РЛ-распознавания ВЦ положены результаты [2] широкомасштабных летно-экспериментальных исследований (ЛЭИ) по регистрации с помощью специальной аппаратуры регистрации, встроенной в приемник импульсно-доплеровской БРЛС с фазированной антенной решеткой в сантиметровом диапазоне волн, РЛ-сигналов, отраженных от различных классов и типов ВЦ, условий их РЛ наблюдения в БРЛС со встроенной аппаратурой регистрации, с последующей обработкой зарегистрированных сигналов на основе использования длительного времени их когерентного накопления (узкополосной доплеровской фильтрации) и анализом информационных свойств сигналов в интересах оценки возможности распознавания ВЦ. Так, на основе анализа спектральных доплеровских портретов (СДП) РЛ-сигналов, отраженных от различных классов и типов реальных ВЦ, экспериментально установлено [2], что представляется возможным на 
этапе первичной обработки сигналов в БРЛС распознать ВЦ по следующим направлениям и принципам:

- по принципу «одиночная цель, с их количеством - групповая цель с количеством групп целей и целей в каждой группе»;

- класс одиночной ВЦ по принципу «самолет с турбореактивным двигателем (ТРД) - самолет с турбовинтовым двигателем (ТВД) - вертолет - ракета»;

- тип одиночной ВЦ из класса «самолет с ТРД»;

- разделяющаяся ВЦ по принципу «отделившаяся одна или несколько одиночных пилотируемых целей от группы самолетов с ТРД - отделившаяся одна или несколько пилотируемых групп целей от группы самолетов с ТРД - отделившаяся ракета от ее носителя-самолета с ТРД»;

- типовой состав групповой воздушной цели (ГВЦ) из класса «самолеты с ТРД».

В таблице [3] в систематизированном виде представлены распознаваемые состояния ВЦ, виды спектральных доплеровских портретов, соответствующие данным состояниям, и признаки распознавания целей.

В дальнейшем возникает необходимость, во-первых, разработать процедуры распознавания ВЦ по вышеуказанным принципам и направлениям и, во-вторых, объединить разработанные процедуры в единый метод комплексного распознавания ВЦ в БРЛС на этапе первичной обработки РЛ-сигналов.

Цель работы - разработать метод комплексного распознавания ВЦ в БРЛС на этапе первичной обработки РЛ-сигналов, объединяющий процедуры распознавания целей по принципу «одиночная цель - групповая цель», класса одиночной ВЦ по принципу «самолет с ТРД - самолет с ТВД - вертолет - ракета», типа одиночной ВЦ из класса «самолет с ТРД», разделяющейся ВЦ и типового состава ГВЦ из класса «самолеты с ТРД».

\section{Процедура распознавания ВЦ по принципу «одиночная цель, с их количеством -} групповая цель с количеством групп целей и целей в каждой группе»

Экспериментально установлено [2], что в данном случае устойчивым признаком распознавания может являться количество локальных максимумов в СДП, а решающее правило основано на анализе количества данных локальных максимумов с дополнительным их стробированием по доплеровской частоте. Так, при количестве локальных максимумов в СДП, равном единице, принимается решение о том, что цель одиночная, в противном случае принимается решение, что цель групповая. Данный признак и решающее правило распознавания воздушных целей положены в основу следующей процедуры распознавания ВЦ.

1. Отраженный от воздушных целей РЛ-сигнал на промежуточной частоте во временной области (рис. 1а) с помощью процедуры быстрого преобразования Фурье (БПФ) преобразуется в частотную область (формируется СДП отраженного от цели РЛ-сигнала) (рис. 1б).

2. В полученном СДП выделяется область средних доплеровских частот спектральных составляющих, соответствующих отражениям сигнала от планеров ВЦ (рис. 1в).

3. Определяются отсчеты доплеровских частот локальных максимумов амплитуд спектральных составляющих сигнала, соответствующих его отражениям от планеров ВЦ и превышающих уровень шумовых спектральных составляющих (рис. 1г). 


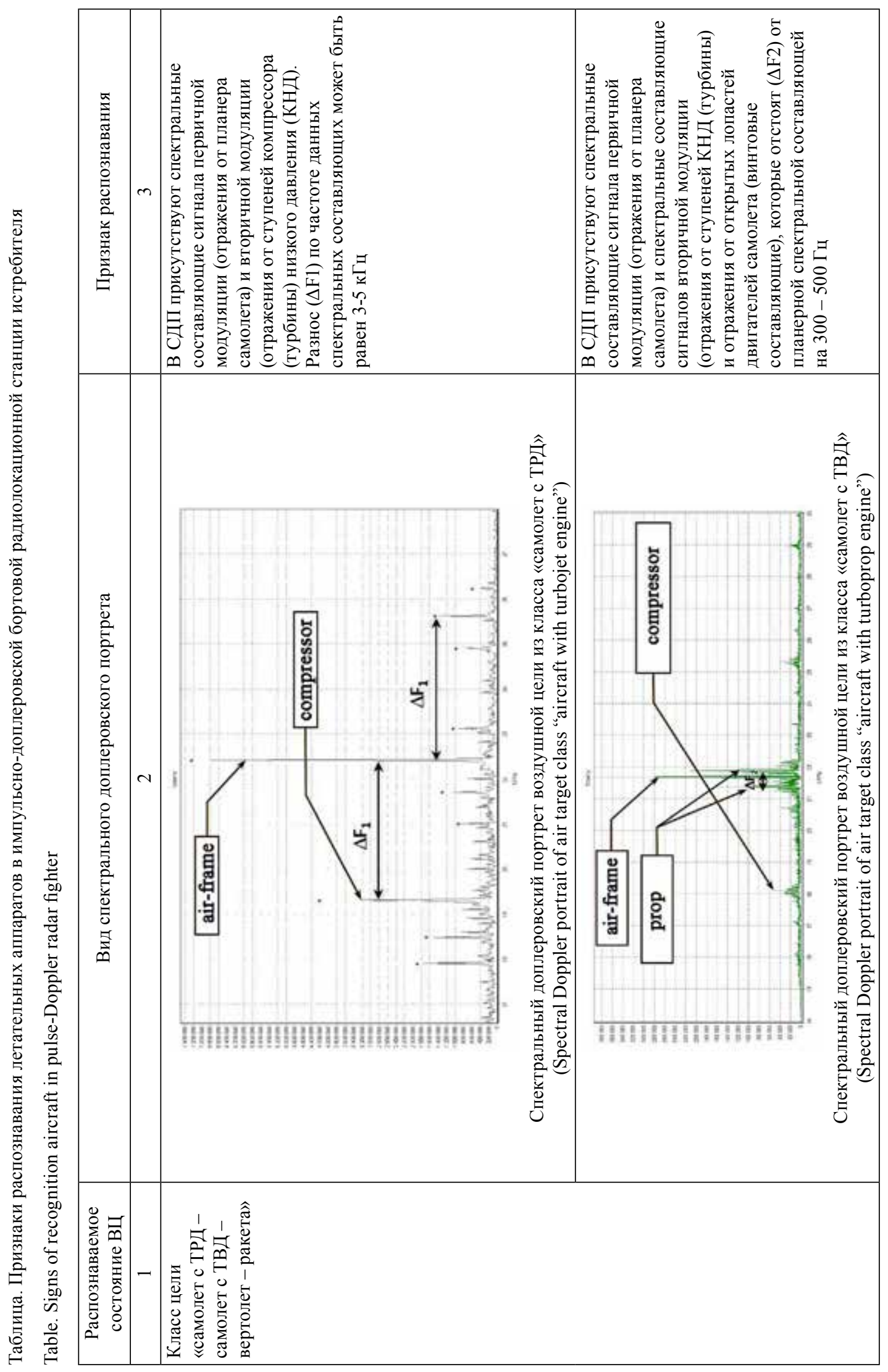




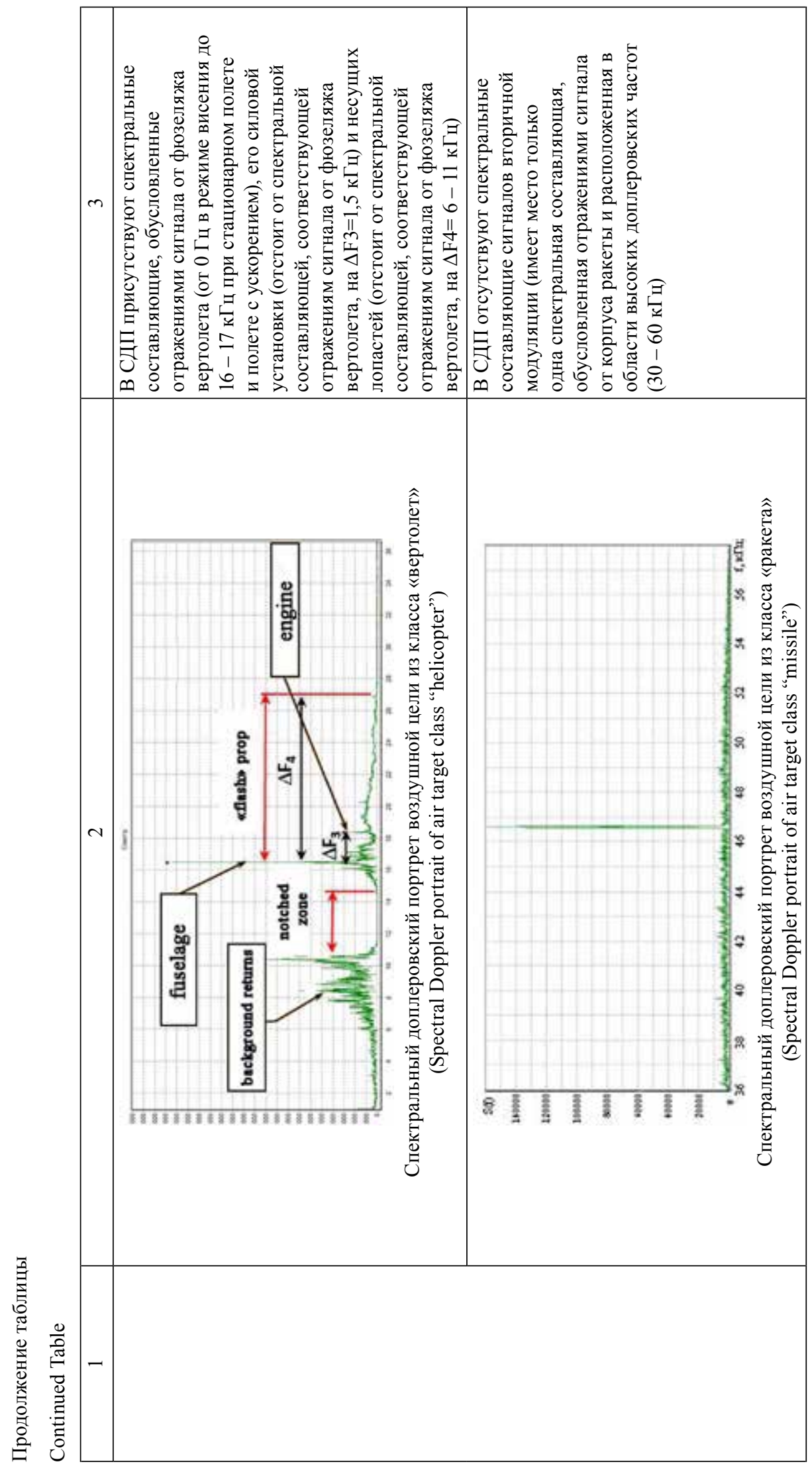




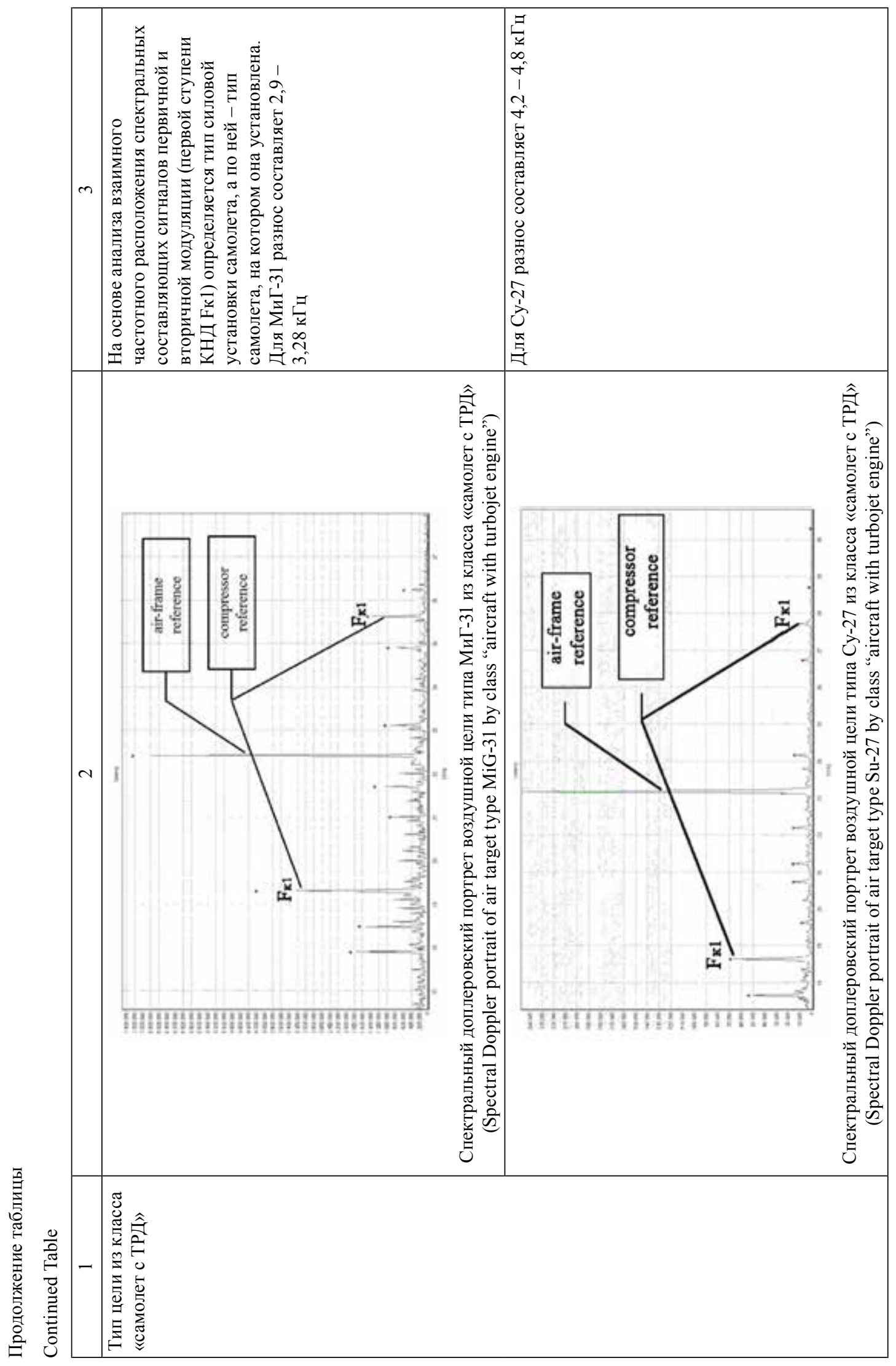




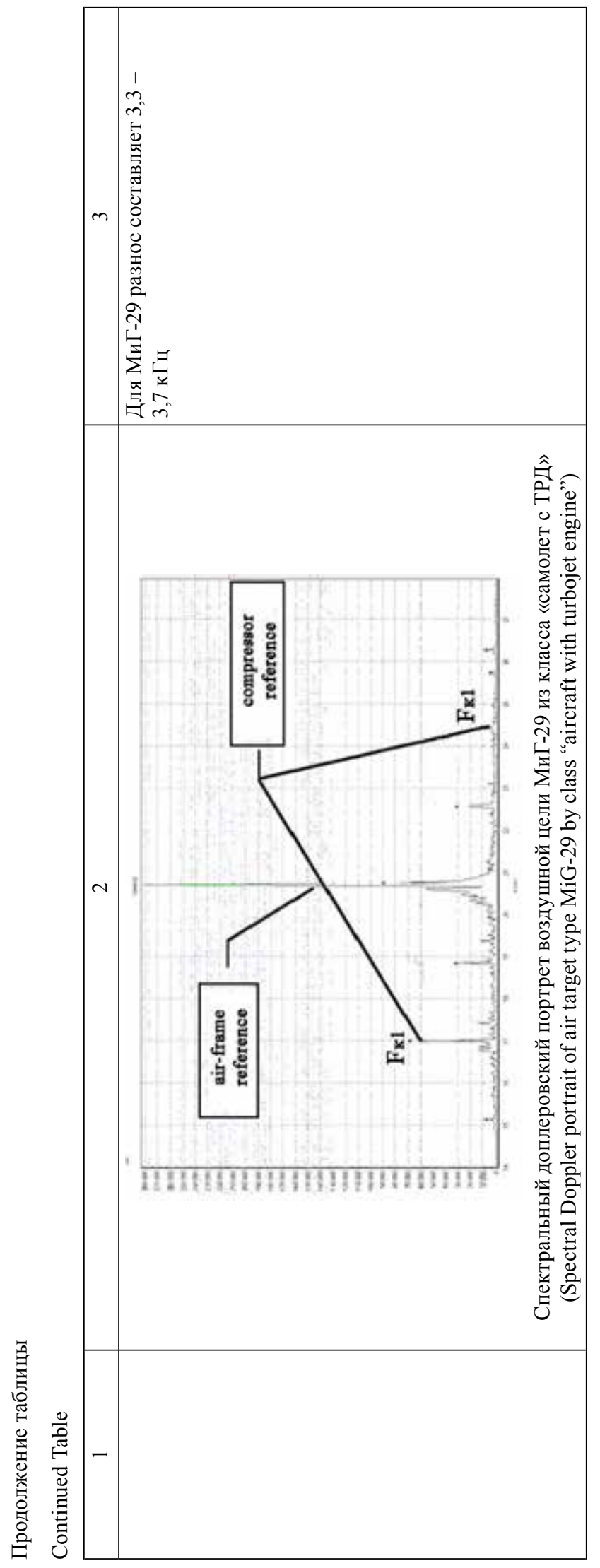




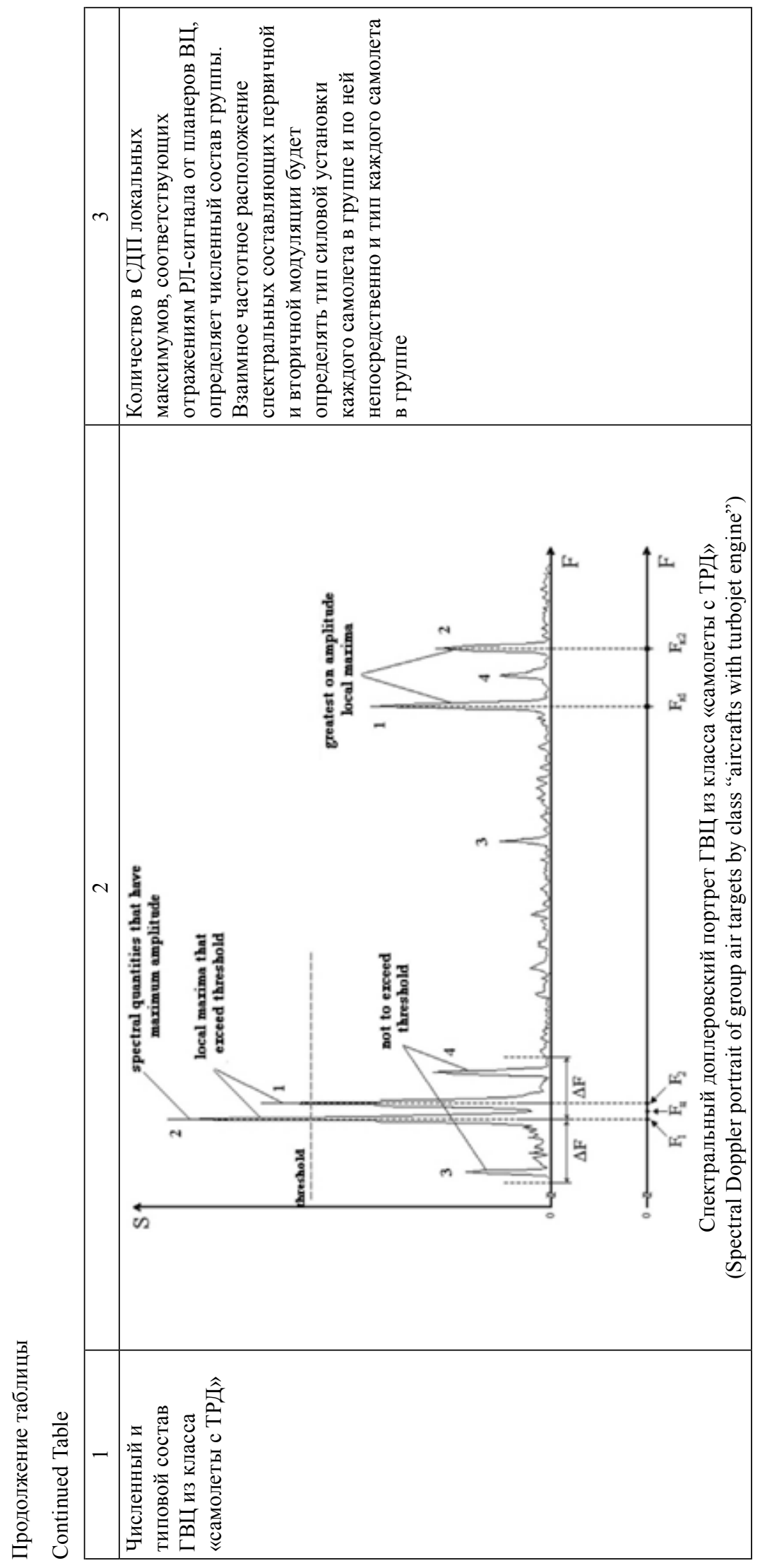




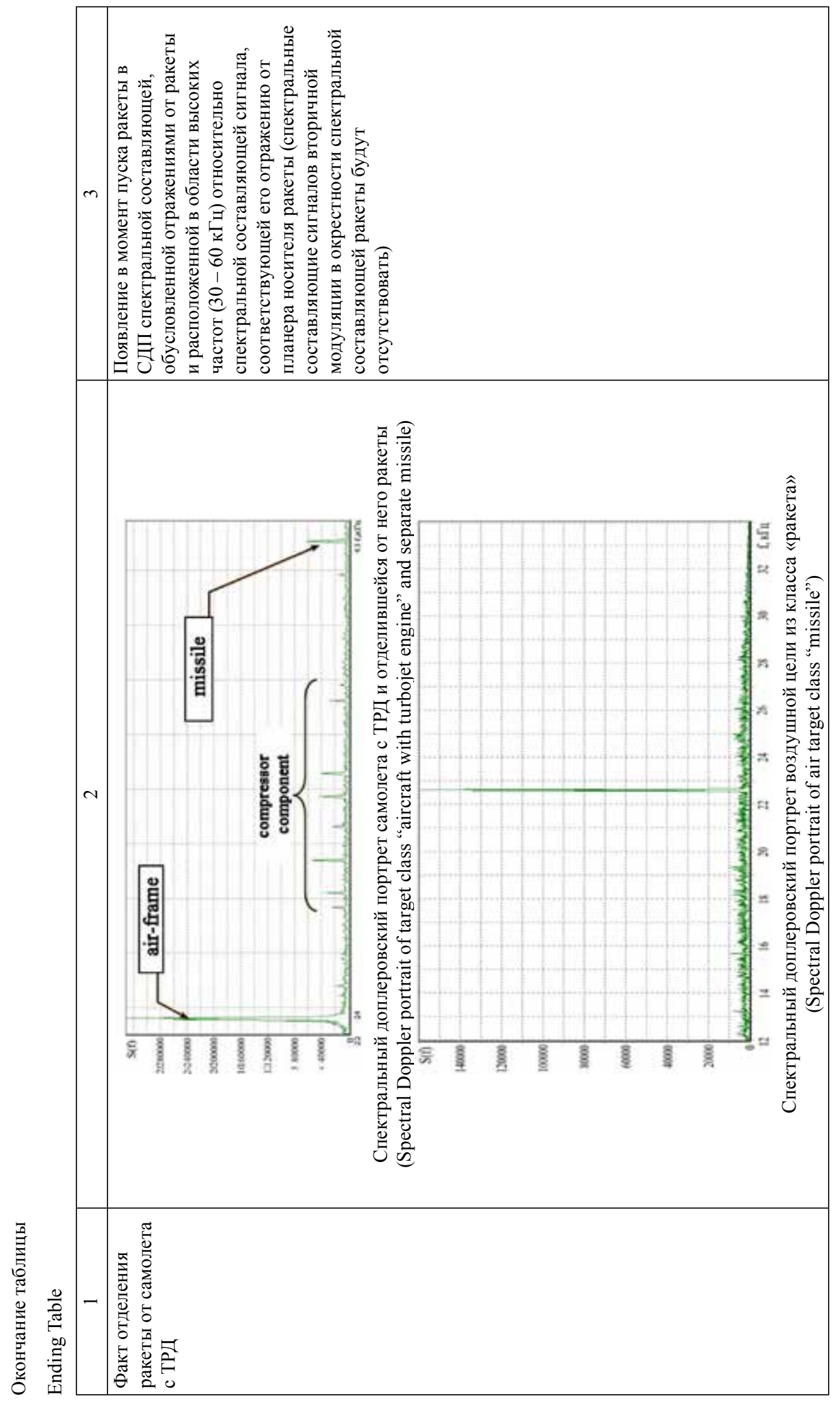




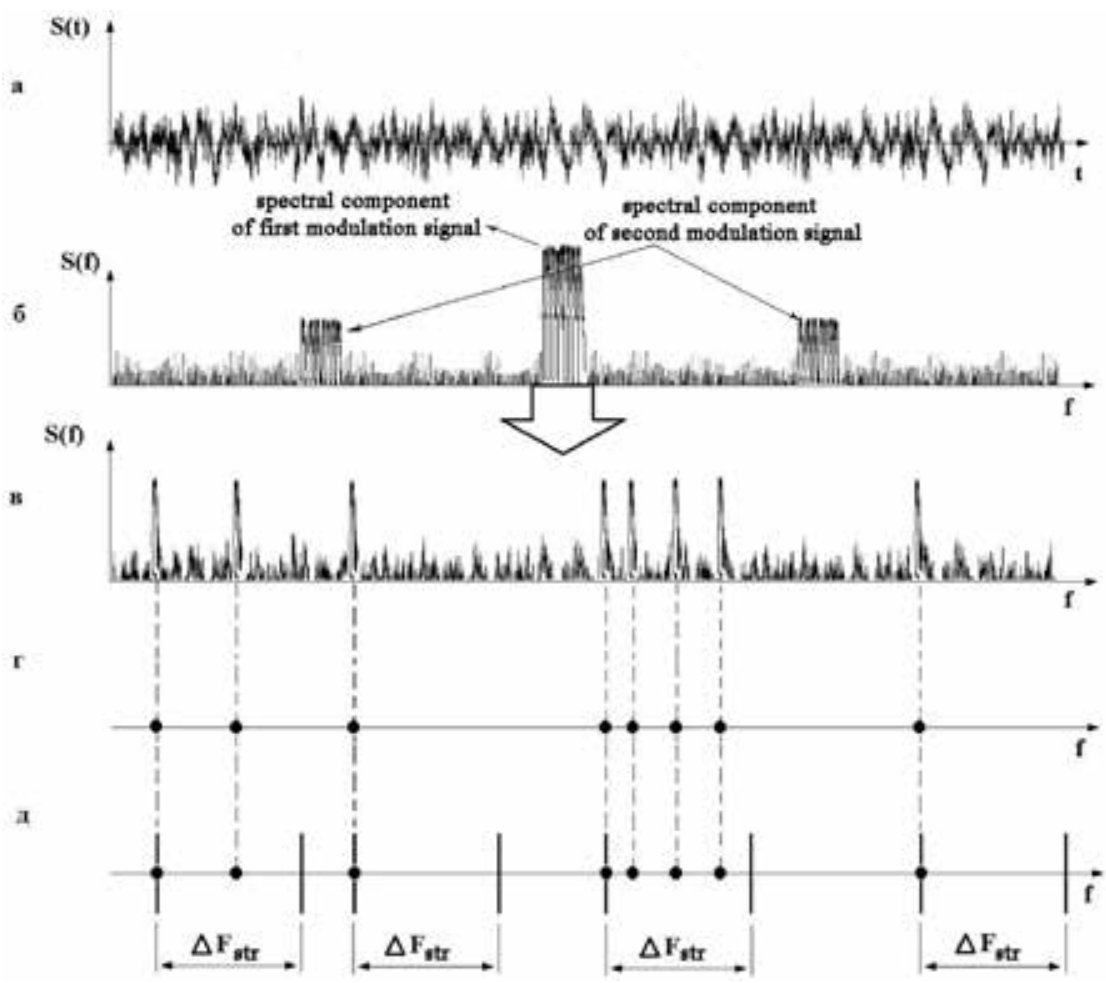

Рис. 1. Эпюры, поясняющие процедуру распознавания

Fig. 1. Curve that illustrate procedure of recognition

4. Определяется значение минимального отсчета доплеровской частоты, соответствующей локальному максимуму амплитуды спектральной составляющей сигнала, отраженного от планера ВЦ (рис. 1г).

5. Осуществляется стробирование по частоте полученных в пункте 3 отсчетов доплеровских частот с шириной строба $\Delta F_{\text {стр}}$, причем левая граница первого строба устанавливается на частотную позицию определенного выше (в пункте 4) минимального отсчета доплеровской частоты, а левые границы других стробов устанавливаются на частотные позиции отсчетов доплеровских частот, не попавших в границы предыдущего строба (рис. 1д).

6. Если в границы строба попали другие отсчеты доплеровских частот, то принимается решение о том, что цель групповая, в противном случае (если в строб не попало больше ни одного отсчета доплеровской частоты) - цель одиночная.

7. Количество стробов, в пределы которых попали другие отсчеты доплеровских частот, определяет количество групп воздушных целей, а количество целей в каждой группе определяется количеством отсчетов доплеровских частот, большем на единицу, попавших в соответствующий строб. Количество стробов, в пределы которых не попал ни один отсчет доплеровской частоты, определяет количество одиночных воздушных целей.

Так, например, согласно приведенным эпюрам (рис. 1а-д), принимается решение о том, что, во-первых, две цели - одиночные, во-вторых, две цели - групповые, причем в первой группе - две цели, а во второй - четыре цели. 


\section{Процедура распознавания класса одиночной ВЦ по принципу «самолет с ТРД - самолет с ТВД - вертолет - ракета»}

Данная процедура заключается в следующем.

1. Исходным условием служит информация о том, что распознаваемая воздушная цель является одиночной (в результате реализации процедуры распознавания ВЦ по принципу «одиночная - групповая», приведенной выше) и получен ее СДП.

2. Если в спектральном доплеровском портрете присутствуют следующие спектральные составляющие (см. СДП в таблице (распознавание класса ВЦ)):

- одна, имеющая максимальную амплитуду (отражения от планера самолета), расположенная в области средних доплеровских частот и превышающая заданный уровень порога $U_{\Pi 1}$;

- две составляющие, отстоящие по частоте слева и справа на величину $\Delta F_{1}$ от спектральной составляющей, имеющей максимальную амплитуду (отражения от первой ступени КНД самолетов с ТРД и ТВД (1 ступень КНД), и превышающие порог $U_{\text {П2 }}\left(U_{\Pi 1}>U_{\Pi 2}\right)$, то принимается предварительное решение, что цель принадлежит либо к классу «самолет с ТРД», либо к классу «самолет с ТВД».

3. Если в спектральном доплеровском портрете дополнительно (к пункту 2) имеются спектральные составляющие, отстоящие по частоте слева и справа на величину $\Delta F_{2}\left(\Delta F_{2}<\Delta F_{1}\right)$ от спектральной составляющей, имеющей максимальную амплитуду (отражения от лопастей двигателей самолета с ТВД), и превышающие порог $U_{\text {Пз }}\left(U_{\Pi 1}>U_{\text {П3 }}>U_{\text {П2}}\right)$, то окончательно принимается решение о том, что цель принадлежит к классу «самолет с ТВД», в противном случае - к классу «самолет с ТРД».

4. Если в СДП присутствуют следующие спектральные составляющие:

- одна, имеющая максимальную амплитуду (отражения от фюзеляжа вертолета), расположенная в области низких доплеровских частот и превышающая заданный уровень порога $U_{\Pi 4}$;

- составляющая, отстоящая по частоте справа на величину $\Delta F_{3}$ от спектральной составляющей, имеющей максимальную амплитуду (отражения от вращающихся частей силовой установки вертолета), и превышающая порог $U_{\text {П5 }}\left(U_{\Pi 4}>U_{\text {П5 }}\right)$;

- совокупность составляющих, отстоящих по частоте справа на величину $\Delta F_{4}\left(\Delta F_{3}<\Delta F_{4}\right)$ от спектральной составляющей, имеющей максимальную амплитуду («всплеск» отражений от лопасти вертолета), и превышающих порог $U_{\Pi 6}\left(U_{\Pi 4}>U_{\Pi 5}>U_{\Pi 6}\right)$, то принимается решение, что цель принадлежит к классу «вертолет».

5. Если в спектральном доплеровском портрете присутствует только одна спектральная составляющая, расположенная в области высоких доплеровских частот и превышающая заданный уровень порога $U_{\Pi 7}$, и отсутствуют составляющие, отстоящие от нее слева и справа на величину $\Delta F_{1}$ и не превышающие порог $U_{\text {п2}}$, то принимается решение, что цель принадлежит к классу «ракета».

Экспериментальным путем установлено [2] следующее:

- область высоких доплеровских частот составляет 30-60 кГц;

- область средних доплеровских частот составляет 18-25 кГц;

- область низких доплеровских частот составляет 0-17 кГц; 
- величина $\Delta F_{1}$ составляет 3-5 кГц;

- величина $\Delta F_{2}$ составляет $0,3-0,5$ кГц;

- величина $\Delta F_{3}$ составляет около 1,5 кГц;

- величина $\Delta F_{4}$ составляет около 6-11 кГц;

- величины соотношения порогов имеют следующие значения:

$U_{\Pi 1}>U_{\text {П2 }}$ больше в 2-4 раза;

$U_{\Pi 3}>U_{\Pi 2}$ больше в 4-5 раз;

$U_{\Pi 4}>U_{\Pi 5}$ больше в 2,5-3 раза;

$U_{\Pi 5}>U_{\text {П6 }}$ больше в 3-4 раза;

$U_{\Pi 2}>U_{\Pi 7}$.

\section{Процедура распознавания типа одиночной воздушной цели из класса «самолет с турбореактивным двигателем»}

Экспериментально установлено [2], что на основе анализа взаимного частотного расположения спектральных составляющих сигналов первичной (отражений от планера самолета) и вторичной модуляции (отражений от вращающихся частей силовой установки самолета) можно определить тип силовой установки самолета с ТРД, а по ней - непосредственно и тип самого самолета, на котором установлен данный тип двигателя.

1. Исходным условием в данной процедуре служит информация о том, что, во-первых, распознаваемая воздушная цель является одиночной (в результате реализации процедуры распознавания ВЦ по принципу «одиночная - групповая») и, во-вторых, цель является представителем класса «самолет с ТРД (в результате реализации процедуры распознавания класса одиночной ВЦ по приниипу «самолет с ТРД - самолет с ТВД - вертолет - ракета»), а также получен полный, с учетом спектральных составляющих сигнала вторичной модуляции, ее спектральный доплеровский портрет (см. СДП в таблице (распознавание типа одиночной цели из класса «самолет с ТРД»)).

2. Определяется отсчет доплеровской частоты, соответствующий максимальной амплитуде спектральной составляющей спектра сигнала, который соответствует его отражениям от планера воздушной цели.

3. Определяется отсчет доплеровской частоты, соответствующий максимальной амплитуде спектральной составляющей спектра сигнала, находящейся слева по доплеровской частоте относительно спектральной составляющей сигнала, отраженного от планера воздушной цели.

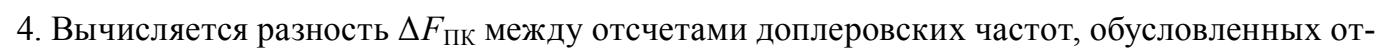

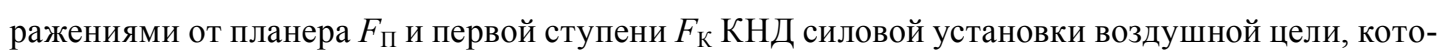
рая соответствует только одному типу цели из класса «самолет с ТРД».

5. Весь диапазон возможных значений оценок разностей $\Delta \hat{F}_{n \kappa}$ априорно разбивается (рис. 2) на $Q$ неперекрывающихся поддиапазонов, при этом нижняя $F_{H q}$ и верхняя $F_{B q}$ границы каждого q-го поддиапазона (q = $1, \ldots, \mathrm{Q})$, соответствующего q-му типу цели, определяются выражениями

$$
\begin{aligned}
& F_{H q}=F_{P i} * n_{1} * N_{J i}, \\
& F_{B q}=F_{P i} * n_{2} * N_{J i},
\end{aligned}
$$


где $F_{P i}$ - максимальная частота вращения ротора КНД силовой установки q-го типа воздушной цели; $n_{1}$ и $n_{2}$ - соответственно минимальное и максимальное значения величины относительных оборотов вращения ротора силовой установки, одинаковые для всех типов воздушных целей; $N_{\text {Лi }}-$ количество лопаток рабочего колеса первой ступени КНД.

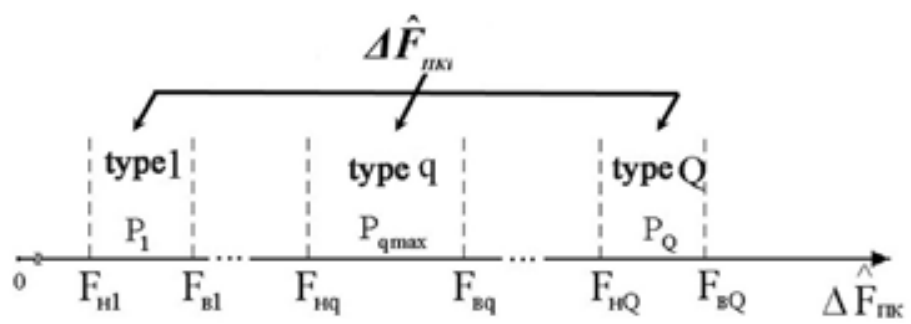

Рис. 2. Диапазоны разностей оценок доплеровских частот

Fig. 2. Range of difference estimate Doppler frequency

6. Определяется номер q-го поддиапазона, в который попала величина $\Delta \hat{F}_{n \kappa}$, и принимается решение о распознавании q-го типа воздушной цели из класса «самолет с ТРД».

Процедура распознавания разделяющейся воздушной цели по принципу «отделившаяся одна или несколько одиночных пилотируемых целей от группы самолетов с ТРД - отделившаяся одна или несколько пилотируемых групп целей от группы самолетов с ТРД - отделившаяся ракета от ее носителя-самолета с ТРД»

1. Исходным условием в данной процедуре распознавания является информация о том, что в результате реализации процедуры распознавания ВЦ по принципу «одиночная - групповая», определено по текущему k-му спектральному доплеровскому портрету (в области средних доплеровских частот), что имеется $N_{k}^{(i)}$ групп целей, каждая из которых состоит из і самолетов, и $M_{k}$ одиночных целей (например, согласно рис. 1д, $M_{k}=2 ; N_{k}^{(i)}=2$, причем в первой группе $i=2$, а во второй $-i=4)$.

2. Данная информация запоминается в качестве эталонной для анализа $k+1$-го и $k+2$-го спектральных доплеровских портретов.

3. По каждому текущему $k+1$-му и $k+2$-му спектральному доплеровскому портрету (в области средних доплеровских частот) в соответствии с приведенной процедурой распознавания ВЦ по принципу «одиночная - групповая» определяются количество $L_{k+1}^{(j)}$ групп целей, количество ј самолетов в каждой группе, а также $Z_{k+1}$ одиночных целей.

4. Сравнивается информация, полученная при анализе $k$-го, $k+1$ и $k+2$ спектральных доплеровских портретов. Если она полностью совпадает $\left(M_{k}=Z_{k+1} ; N_{k}^{(i)}=L_{k+1}^{(j)}\right.$ и для каждой группы $i=j$ ), то принимается решение о том, что цель не разделилась и информация, полученная на основе анализа $k$-го спектрального доплеровского портрета $\left(N_{k}^{(i)}\right.$ и $\left.M_{k}\right)$, сохраняется в качестве эталонной для следующего анализа $k+3$-го спектрального доплеровского портрета. 
В противном случае (если информация, полученная при анализе $k$-го, $k+1$-го и $k+2$-го спектральных портретов не совпадает) принимается решение о разделении цели и появлении новых групп $L_{k+1}^{(j)}$, каждая из которых состоит из $j$ самолетов, и количества $Z_{k+1}$ одиночных целей. Данная информация сохраняется в качестве эталонной для следующего анализа $k+3$-го спектрального доплеровского портрета и т.д.

5. Параллельно в спектральном доплеровском портрете анализируется область высоких доплеровских частот. При появлении в некоторый момент времени спектральной составляющей, превысившей установленный уровень порога $U_{\Pi 7}$, и отсутствии спектральных составляющих, отстоящих от нее слева и справа на величину $\Delta F_{1}$ и не превышающих порог $U_{\text {П2 }}$ (таблица, распознаваемое состояние - факт отделения ракеты класса «воздух-воздух» от самолета с ТРД), принимается решение, что ракета отделилась от ее носителя.

\section{Процедура распознавания типового состава ГВЦ из класса «самолеты с ТРД»}

Физическая сущность данной процедуры заключается в том, что взаимное частотное расположение совокупностей спектральных составляющих в СДП сигналов первичной и вторичной модуляции определяют, как и для одиночной воздушной цели, тип силовой установки каждого самолета в группе, а по нему - непосредственно типовой состав группы в целом.

1. Исходным условием является информация о том, что по спектральному доплеровскому портрету (в области средних доплеровских частот) определено наличие одной ГВЦ из класса «самолеты с ТРД» и получен полный, с учетом спектральных составляющих сигналов вторичной модуляции, ее спектральный доплеровский портрет (см. СДП (распознавание типового состава ГВЦ из класса «самолеты с ТРД»)).

2. Определяется отсчет доплеровской частоты, соответствующий максимальной амплитуде спектральной составляющей спектра сигнала, который соответствует его отражениям от планера одного из самолетов из этой группы (спектральная составляющая № 2).

3. Слева и справа в полосе частот $\pm \Delta F_{\text {стр }}$ относительно частоты спектральной составляющей спектра сигнала, имеющей максимальную амплитуду, определяются отсчеты доплеровских частот локальных максимумов спектра сигнала и их общее количество, которые превысили установленный порог (спектральные составляющие № 1 и 2), что соответствует $J$-му количеству самолетов в группе.

4. По выявленным отсчетам доплеровских частот локальных максимумов, находящимся в полосе частот $\pm \Delta F_{\text {стр }}$ относительно спектральной составляющей, имеющей максимальную

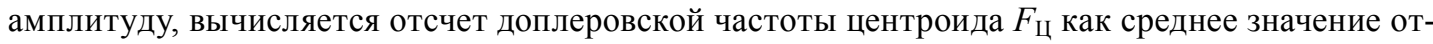
счетов доплеровских частот локальных максимумов.

5. Определяются отсчеты доплеровских частот локальных максимумов, имеющих наибольшие амплитуды, количество которых равно количеству локальных максимумов, находящихся в полосе доплеровских частот $\pm \Delta F_{\text {стр }}$ относительно спектральной составляющей с максимальной амплитудой, соответствующей отражению сигнала от планера одного из самолетов группы, и находящихся справа на частотах, превышающих значение $\pm \Delta F_{\text {стр }}$ (локальные макси-

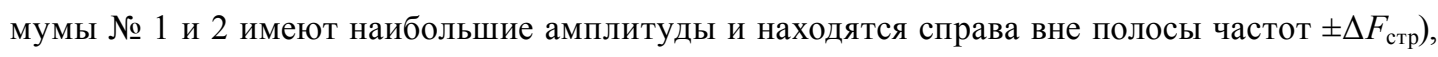


которые обусловлены отражениями сигнала от лопаток первой ступени КНД каждого $j$-го $(j=1, \ldots, \mathrm{J})$ самолета группы.

6. Определяются разности $\Delta F_{ц к j}$ между значениями доплеровских частот, соответствую-

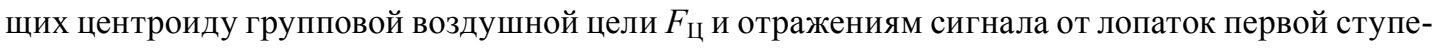
ни $F_{\text {К1 }}$ и $F_{\text {К2 }}$ компрессора (турбины) низкого давления двигателя каждого $j$-го самолета группы, которые соответствуют только одному из распознаваемых типу воздушной цели из класса «самолет с турбореактивным двигателем».

7. Весь диапазон возможных значений оценок разностей $\Delta F_{\text {цКj }}$ априорно разбивается (рис. 3) на Q неперекрывающихся друг с другом поддиапазонов, при этом нижняя $F_{H q}$ и верхняя $F_{B q}$ границы каждого q-го поддиапазона $(\mathrm{q}=1, \ldots \mathrm{Q})$ соответствующего і-му типу цели $(\mathrm{i}=1, \ldots \mathrm{I})$, определяются выражениями (1) и (2).

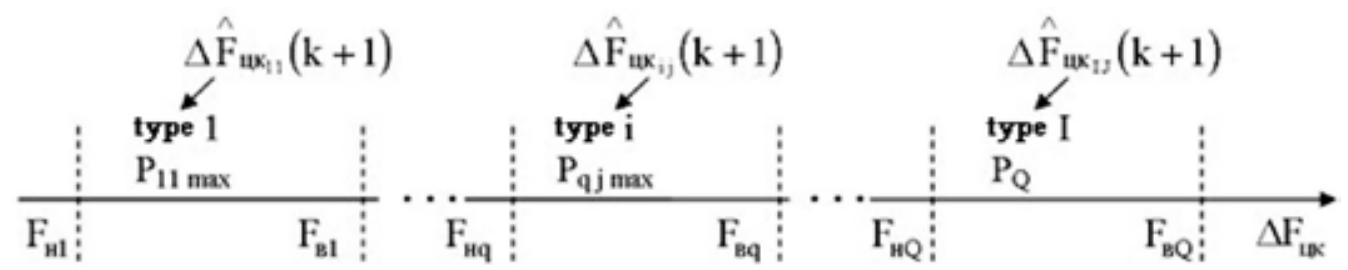

Рис. 3. Разбиение диапазона возможных значений оценок разностей планерных и компрессорных составляющих

Fig. 3. Separate range probably signs estimate difference air-frames and compressor elements

8. Определяются номера $\mathrm{i}-\mathrm{x}(\mathrm{i}=1, \ldots, \mathrm{I})$ поддиапазонов, в которые попала величина $\Delta \hat{F}_{L K j}$, и принимается решение о том, что ј-й самолет в группе имеет і-й тип из класса «самолеты с турбореактивными двигателями».

\section{Метод комплексного распознавания ВЦ в БРЛС на этапе первичной обработки РЛ-сигналов}

На рис. 4 представлена структура метода комплексного распознавания ВЦ в БРЛС на этапе первичной обработки РЛ-сигналов, объединяющего вышеприведенные процедуры распознавания целей по принципу «одиночная цель», класса одиночной ВЦ по принципу «самолет с ТРД - самолет с ТВД - вертолет - ракета», типа одиночной ВЦ из класса «самолет с ТРД», разделяющейся ВЦ и типового состава ГВЦ из класса «самолеты с ТРД».

Сущность предлагаемого метода заключается в следующем.

1. На вход процедуры распознавания ВЦ по принципу «одиночная - групповая» поступает спектральный доплеровский портрет $S(f)$ отраженного от воздушной цели РЛ-сигнала (в виде амплитуд с соответствующими отсчетами доплеровских частот), полученный путем его преобразования из временной области в частотную на основе процедуры БПФ. Осуществляется распознавание воздушной цели по принципу «одиночная - групповая» с определением количества одиночных целей, количество групп целей и количество целей в каждой группе.

2. Если принято решение о том, что цель одиночная, то осуществляется распознавание класса ВЦ по принципу «самолет с ТРД - самолет с ТВД - вертолет - ракета». 


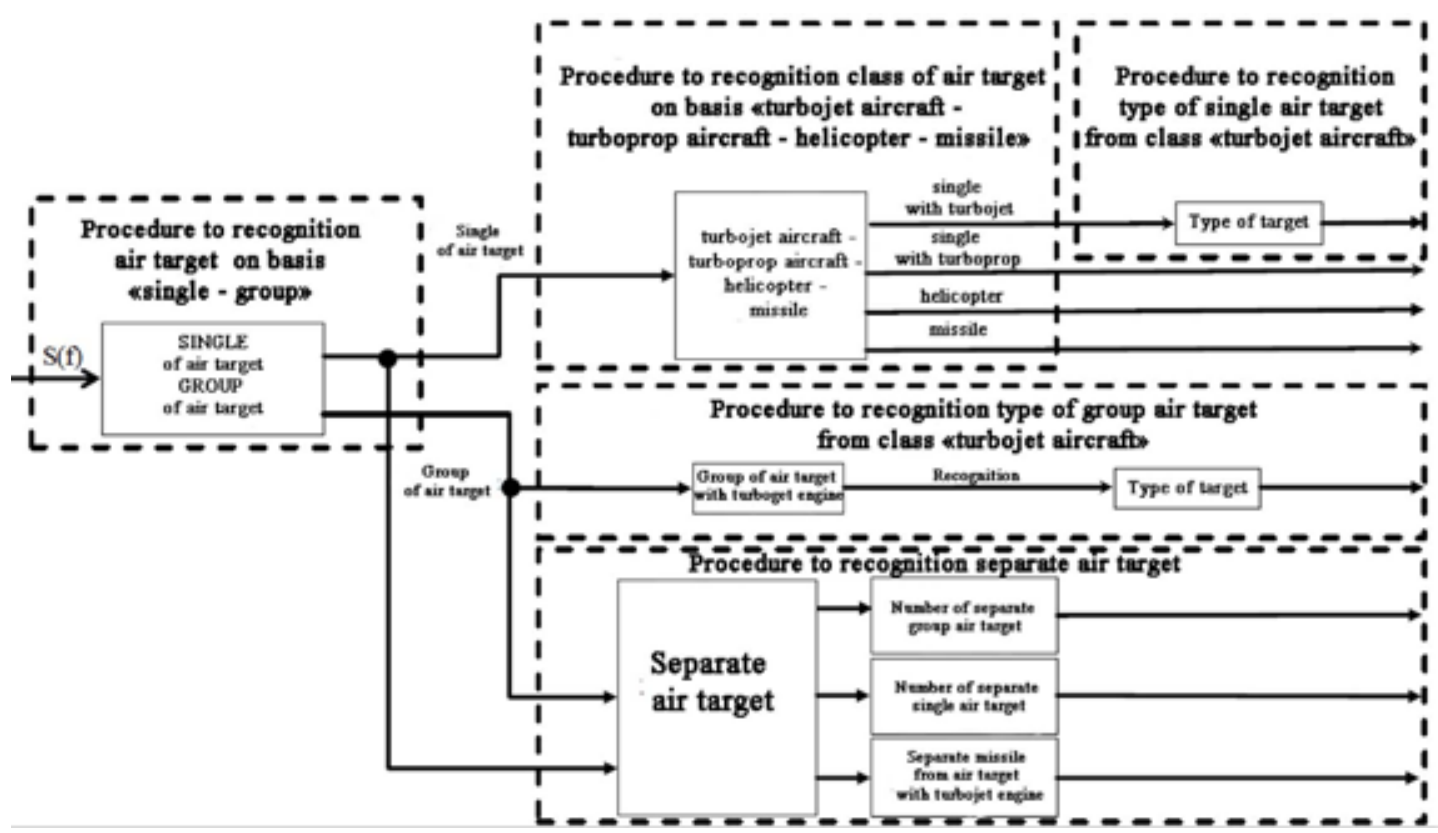

Рис. 4. Метод комплексного распознавания воздушных целей на этапе первичной обработки сигнала

Fig. 4. Method of air targets complex recognition in air-based pulse-Doppler radar on first step analyse signal

3. Если принято решение о том, что цель одиночная и из класса «самолет с ТРД», то осуществляется распознавание типа одиночной воздушной цели.

4. Параллельно со вторым и третьим этапами, если приняты решения о том, что имеется определенное количество одиночных воздушных целей групп целей и количество целей в каждой группе, осуществляется распознавание разделяющейся воздушной цели.

5. Если же на первом этапе принято решение о том, что цель групповая, то осуществляется распознавание типового состава ГВЦ и параллельно распознавание разделяющейся воздушной цели.

В результате совместной реализации описанных выше процедур, в общем случае, на выходе метода комплексного распознавания воздушных целей по спектральным доплеровским портретам на этапе первичной обработки сигналов имеет место следующая информация:

- о количестве одиночных воздушных целей;

- о количестве групп воздушных целей;

- о количестве целей в каждой группе;

- о типе одиночной воздушной цели;

- о типовом составе групповой воздушной цели;

- о том, что одиночная воздушная цель является самолетом с турбовинтовым двигателем;

- о том, что одиночная воздушная цель является вертолетом;

- о том, что одиночная воздушная цель является ракетой;

- о том, что произошло разделение пилотируемой группы целей;

- о том, что не произошло разделение пилотируемой группы целей;

- о том, что произошло отделение ракеты от ее носителя. 
Таким образом, с учетом результатов экспериментальных исследований информационных свойств РЛ, отраженных от реальных воздушных целей, разработан метод комплексного их распознавания в импульсно-доплеровской БРЛС на этапе первичной обработки РЛ-сигналов, объединяющий процедуры распознавания целей по принципу «одиночная цель - групповая цель», класса одиночной ВЦ по принципу «самолет с ТРД-самолет с ТВД-вертолет - ракета», типа одиночной ВЦ из класса «самолет с ТРД», разделяющейся ВЦ и типового состава ГВЦ из класса «самолеты с ТРД».

\section{Список литературы / References}

[1] Богданов А.В., Коротков С.С., Кучин А.А., Бондарев В.Н., Лютиков И.В. Концепция распознавания воздушных целей в авиационном радиолокационном комплексе, Журнал СФУ. Техника и технологии, 2016, 9(3), 320-331. [Bogdanov A.V., Korotkov S.S., Kuchin A.A., Bondarev V.N. The concept of recognition of air targets in the aviation radar complex, Journal of Siberian Federal University. Engineering and technology, 2016, 9(3), 320-331 (in Russian)]

[2] Богданов А.В., Васильев О.В., Каневский М.И., Коротков С.С., Миронович С.Я., Кучин А.А., Анциферов А.А., Закомолдин Д.В. Результаты летно-экспериментальных исследований по оценке возможностей всестороннего распознавания воздушных целей в импульсно-доплеровской РЛС воздушного базироваия в сантиметровом диапазоне волн, Усnехи современной радиоэлектроники, 2016, 11, 174 - 179. [Bogdanov A.V., Vasiliev O.V., Kanevskiy M.I., Korotkov S.S., Mironovich S.Y., Kuchin A.A., Antsiferov A.A., Zakomoldin D.V. The results of experimental studies on assessment of comprehensive air target recognition in centimeter band by airborne pulse doppler radar, Advances in modern electronics, 2016, 11, 174 - 179 (in Russian)]

[3] Богданов А.В., Лобанов А.А. Признаки распознавания воздушных целей в бортовой радиолокационной станции истребителя на основе анализа спектральных доплеровских портретов радиолокационных сигналов, отраженных от реальных ЛА, Вестник ВА ВКО, 2019, 3, 99-104. [Bogdanov A.V., Lobanov A.A. Signs of recognition air targets in airborne pulse doppler radar fighter based on analyse spectral Doppler portrait created by radar signals reflecting from real air targets, Transaction of the Military Aerospace Defence Academy, 2019, 3, 99-104 (in Russian)] 